$12-11-2018$

\title{
Taking Free Flap Surgery Abroad: A Collaborative Approach to a Complex Surgical Problem.
}

\author{
Brian Swendseid, MD \\ Thomas Jefferson University \\ Patrick Tassone, MD \\ Thomas Jefferson University \\ Patrick Jean Gilles, MD \\ University of Haiti \\ Magda Pavrette, MD \\ Ebollwensthjisofintedaitdditional works at: https://jdc.jefferson.edu/otofp \\ Wutthetofstewatplaryngology Commons, and the Surgery Commons

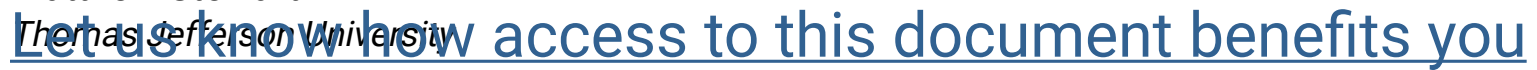

\section{Beeommergefd/Citantiomal authors}

Swendseid, MD, Brian; Tassone, MD, Patrick; Gilles, MD, Patrick Jean; Pavrette, MD, Magda; Stewart, Matthew; Batatope, Mercy; Weed, MD, Donald; Cognetti, MD, David; Luginbuhl, MD, Adam J.; and Curry, MD, Joseph, "Taking Free Flap Surgery Abroad: A Collaborative Approach to a Complex Surgical Problem." (2018). Department of Otolaryngology - Head and Neck Surgery Faculty Papers. Paper 41.

https://jdc.jefferson.edu/otofp/41

This Article is brought to you for free and open access by the Jefferson Digital Commons. The Jefferson Digital Commons is a service of Thomas Jefferson University's Center for Teaching and Learning (CTL). The Commons is a showcase for Jefferson books and journals, peer-reviewed scholarly publications, unique historical collections from the University archives, and teaching tools. The Jefferson Digital Commons allows researchers and interested readers anywhere in the world to learn about and keep up to date with Jefferson scholarship. This article has been accepted for inclusion in Department of Otolaryngology - Head and Neck Surgery Faculty Papers by an authorized administrator of the Jefferson Digital Commons. For more information, please contact: JeffersonDigitalCommons@jefferson.edu. 


\section{Authors}

Brian Swendseid, MD; Patrick Tassone, MD; Patrick Jean Gilles, MD; Magda Pavrette, MD; Matthew Stewart; Mercy Batatope; Donald Weed, MD; David Cognetti, MD; Adam J. Luginbuhl, MD; and Joseph Curry, MD 
Title: Taking Free Flap Surgery Abroad: A Collaborative approach to a complex surgical problem

Corresponding author:

Brian Swendseid, MD

925 Chestnut St, $7^{\text {th }}$ Floor

Philadelphia, PA 19107

Brian.swendseid@jefferson.edu

215-955-6760

Authors:

Brian Swendseid MD ${ }^{1}$

Patrick Tassone, $\mathrm{MD}^{1}$

Patrick Jean Gilles, $\mathrm{MD}^{2}$

Magda Pavrette, $\mathrm{MD}^{2}$

Matthew Stewart ${ }^{3}$

Mercy Babatope ${ }^{3}$

Donald Weed, $\mathrm{MD}^{4}$

David Cognetti, $\mathrm{MD}^{1}$

Adam Luginbuhl, $\mathrm{MD}^{1}$

Joseph Curry, $\mathrm{MD}^{1}$

Author Affiliations

1. Department of Otolaryngology - Head \& Neck Surgery

Thomas Jefferson University, Philadelphia, PA

2. University of Haiti, Port-Au-Prince, Haiti

3. Sidney Kimmel Medical College, Philadelphia, PA

4. Department of Otolaryngology - Head \& Neck Surgery University of Miami, Miami, FL

Conflicts of Interest: none

Funding disclosure: none

Keywords: surgical outreach, free tissue transfer, surgical outreach, Haiti

This manuscript was presented as an oral presentation at the AAO-HNSF 2017 Annual Meeting. 


\begin{abstract}
Accessibility to healthcare, especially complex surgical care, represents one of the major healthcare disparities in developing countries. While surgical teams may be willing to travel to these areas to help address these needs, there are many logistical and ethical dilemmas inherent in this pursuit. We reviewed our approach to the establishment of the team-based surgical outreach program, wherein we perform head and neck free-tissue transfer surgery in Haiti. We describe the challenges encountered in the delivery of surgical care as well as ethical dilemmas relevant to surgical outreach trips, highlighting an approach reliant on strong local cooperation. Despite the obstacles in place, our experience shows that free-flap surgery can be successfully and ethically performed in these areas of great need.
\end{abstract}

\title{
Identifying a need for specialized care and training
}

Haiti is the most underserved nation in the Western Hemisphere.1 Our group initially travelled to Haiti in 2014 to provide otolaryngologic care to a remote hospital. Through that effort, we met Dr. Jean Gilles, a surgeon who identified an opportunity for free tissue transfer to reconstruct patients with head and neck tumors, a treatment currently unavailable in Haiti, and expressed a clear desire for specialty education. Several groups have successfully performed free flap surgery outreach trips abroad. ${ }^{2,3}$ Therefore, our combined head and neck reconstructive team, including members from the University of Haiti, Thomas Jefferson University, and the University of Miami assessed the feasibility of free flap surgery in Haiti.

Major operations in Haiti present many significant challenges: few hospitals have infrastructure for complex surgical care, local support staff are often unfamiliar with such surgeries, equipment and materials are scarce, and adequate follow-up is difficult to provide. Moreover, even under the best circumstances at high-volume US centers, free tissue transfer is challenging and resource intensive. Free tissue transfers frequently have operative times over 6 hours, an average cost for surgical and aftercare of $\$ 36,000-\$ 80,000$ per patient ${ }^{4}$, and failure rates are not zero. ${ }^{5-8}$ However, there are advantages to the development of a local program for such a procedure: it allows for patients to be treated near home, provides training to local teams, and can be accomplished at a lower cost.

Our collaborative team relies on the University of Haiti clinicians to identify patients who would most benefit. Our group identified large benign mandibular and maxillary tumors, such as ameloblastomas, as prime candidates for several reasons. First, they occur in younger patients with high functional status who are likely to tolerate surgery well. Second, their benign pathology can be effectively treated with surgery alone. This is important given Haiti's lack of available adjuvant radiation therapy. Third, patients with mandibular tumors often do not present to a specialist until tumors are quite large, causing significant oral dysphagia, as well as severe disfigurement and social isolation. This impacts patient's ability to work and hence induces economic pressure for already marginalized individuals. Finally, these patients have great potential to benefit from free tissue transfer. Complete tumor resection offers high likelihood of cure, but without reconstruction, significant functional and aesthetic deficits occur. For larger tumors, the functional and aesthetic advantage of vascularized bony reconstruction greatly exceeds plate reconstruction or non-vascularized reconstruction. Based on this, the potential benefit to the individual patient and physician community merited the utilization of resources.

\section{Delivery of Care}


We assessed the local environment to determine how to best deliver operative and postoperative care. We partnered with a hospital and organization with operating room facilities and a postoperative care unit with space to house our team. Our surgical team collaborated with the a highly experienced University of Haiti anesthesia team organized by Dr. Magda Pavrette. Such partnerships are critical for identification of need, triage, effective communication, and continuity of care.

Medications for surgery and anesthesia were either obtained locally through St Luc's hospital or donated by our home institutions. Surgical instruments were brought by our surgical team. This required careful planning to ensure that all necessary instrumentation was functional and avoid having to abort a partially completed procedure. We use a checklist system and planned redundancy, especially for any instrumentation likely to fail (eg, electric drills and saws). Power supply and reliability of local machinery such as autoclaves varies and redundancy avoids delays from system failure. Given the weight and fragile nature of an operating microscope, we performed microvascular anastomosis with loupe magnification. Although loupe magnification has less magnification than an operative microscope, it has a long-standing record of efficacy.

At our institution, many patients who undergo a mandibular free flap reconstruction also undergo temporary tracheostomy for airway protection. However, tracheotomy requires specialized nursing care and can place additional demands on local providers. In many of the patients we care for in Haiti, we have been able to manage the airway postoperatively with nasal trumpets, bypassing oral obstruction and simplifying postoperative nursing care. Additionally, opioid analgesia in the postoperative setting is minimized. It is our practice to use ketoroloac, an intravenous non-steroidal anti-inflammatory drug, to avoid risks of respiratory suppression.

\section{Post-surgical care:}

As our travelling team's time in Haiti for each trip is finite, patient post-surgical care and follow-up is largely in the hands of the local providers. This again highlights the critical need for adequate communication, coordination and collaboration between teams and providers. We employed a gradually escalated model where few complex procedures were completed on our first trip to focus more education and surgical preparation. Furthermore, we planned for additional days of observation prior to departure. To address the possibility of delayed complications, we developed protocols for plans of management as well as open lines of communication for postoperative questions via phone and email with the host team.

\section{Conclusion:}

Establishing a surgical outreach program to perform free-flap surgery abroad has been a highly rewarding experience with many challenges requiring creative solutions. Our experience has made it clear that a team-based model that relies heavily on collaboration with local health care providers is an effective method to ensure that the appropriate patient health needs are being addressed, facilitates preoperative selection, surgical and postsurgical care. Moreover, this allows for exchange of knowledge and expertise between local and travelling teams, strengthening education and partnerships. 


\section{References}

1. Rice S, Graff C, Lewis J. Poverty and Civil War: What Policymakers Need to Know. SSRN Electronic Journal. 2006. doi:10.2139/ssrn.1015091.

2. Mofikoya BO, Ugburo AO. Early experiences with microvascular free tissue transfer in Lagos, Nigeria. Nigerian Journal of Surgery. 2014;20(1):35-37.

3. Ragbir M, Ali T, Naraynsigh V, Ramdass M, Romany S, Mohammed F. The use of loop magnification in microsurgery in the third world: A Trinadad experience. Int J Surg. 2001;2.

4. Gao, L.L., Basta, M., Kanchwala, S.K., Serletti, J.M., Low, D.W., Wu, L.C., 2017. Costeffectiveness of microsurgical reconstruction for head and neck defects after oncologic resection. Head Neck 39, 541-547. https://doi.org/10.1002/hed.24644

5. Rosado P, Cheng H-T, Wu C-M, Wei F-C. Influence of diabetes mellitus on postoperative complications and failure in head and neck free flap reconstruction: a systematic review and metaanalysis. Eisele DW, ed. Head \& neck. 2015;37(4):615-618. doi:10.1002/hed.23624.

6. Corbitt C, Skoracki RJ, Yu P, Hanasono MM. Free flap failure in head and neck reconstruction. Head \& neck. 2014;120(Suppl 1):n/a-n/a. doi:10.1002/hed.23471.

7. Yamashiro M, Hasegawa K, Uzawa N, et al. Complications and Outcome of Free Flap Transfers for Oral and Maxillofacial Reconstruction: Analysis of 213 Cases. Oral Science International. 2009;6(1):46-54. doi:10.1016/S1348-8643(09)80013-X.

8. Dautremont JF, Rudmik LR, Yeung J, et al. Cost-effectiveness analysis of a postoperative clinical care pathway in head and neck surgery with microvascular reconstruction. Journal of otolaryngology - head \& neck surgery $=$ Le Journal d'oto-rhino-laryngologie et de chirurgie cervico-faciale. 2013;42(1):59. doi:10.1186/1916-0216-42-59. 